\title{
Creating Online Instruction that is Accessible, Usable, and Inclusive
}

\author{
Sheryl Burgstahler \\ College of Education \\ University of Washington
}

\begin{abstract}
Author Note
Dr. Sheryl Burgstahler is the Founder of the DO-IT and UW-IT Access Technology Centers at University of Washington (UW). These Centers are part of the unit she continues to direct, Accessible Technology Services. She is an Affiliate Professor in the UW College of Education, teaches Disability Studies at City University of New York, and is on the advisory board of the UW Online Learning Certificate Program.
\end{abstract}




\begin{abstract}
As a consequence of the COVID19 pandemic, we have witnessed a swift movement of onsite and hybrid courses to fully online formats. This development has created an urgent need for the design and delivery of online content and engagement mechanisms that are equitable for all students. There is little evidence that many of these courses are accessible to, usable by, and inclusive of students with disabilities. The author of this article discusses challenges students with disabilities face in accessing online content and engaging in online activities as well as choices that instructors and online course designers can make with respect to pedagogy and information technology (IT) to ensure that their classes are accessible to, usable by, and inclusive of all students. She introduces for those new to this field the potential of the universal design (UD) framework to inform the design of online learning that addresses the needs of students with a wide range of characteristics.
\end{abstract}

Keywords: disability, accessibility, universal design, inclusion 


\section{Creating Online Instruction that is Accessible, Usable, and Inclusive Barriers to Online Learning for Students with Disabilities}

Online learning is often promoted as a way for anyone to engage in courses from anywhere using any device. However, students with disabilities that affect their sight, hearing, mobility, learning, attention, and/or communication can often face accessibility barriers while trying to participate in online learning opportunities.

Little reported research examines factors that influence the success of students with disabilities in online learning. Even studies about performance differences of student subgroups, such as those defined by gender, age, and race, rarely explore differences between students with and without disabilities (e.g., Xu \& Jaggars, 2014). Further, studies about online learning and disability often focus on one or several disability types (e.g., Anderson, 2020) and therefore one cannot draw conclusions about the experiences of students with other types of disabilities.

Challenges and solutions related to the accessibility of online learning from the perspectives of students with disabilities and educators have been reported in the literature (Case \& Davidson, 2011; Durre, Richardson, Smith, Shulman, \& Steele, 2015; Fichten, et al., 2009; Keeler \& Horney, 2007; Raes, Schellens, DeWever, \& Vanderhover, 2012; Seale \& Cooper, 2009; Smith, 2020; Vasquez, Forbush, Mason, Lockwood, \& Gleed, 2011; University of Washington, 2019). However, an informal review of reported research and practice suggests that the needs of students with disabilities are not routinely considered when online courses are being developed (Kinash, Crichton, \& Rupnow, 2004; Roberts, Satkyjgykyjova, \& Park, 2015; Center on Universal Design in Education, n.d.). The reactive approach-providing accommodations for specific students with documented disabilities enrolled in individual courses - is typically applied to address accessibility issues once a student expresses a need for course modifications 
through a disability services unit; included are the need for captions on videos for students who are deaf; and the need for documents in accessible formats for students who have reading-related disabilities or are blind and use screen readers to speak aloud text-based content. At best, the accommodations approach results in the student with a disability gaining access to course content at a later date than other students. At worst, the student cannot access the content and engage in opportunities available to other students.

\section{The Universal Design Framework}

An alternative to the accommodations-only approach to access for students with disabilities is to apply universal design (UD) principles when an online course or activity is being developed in order to avoid creating common barriers to students with disabilities and thus reduce the need for accommodations. UD is consistent with the understanding of disability as a social construct. The "social model" of disability and other integrated approaches within the field of disability studies (DePoy \& Gibson, 2008; Gabel \& Peters, 2010) considers variations in abilities a normal part of the human experience and suggests that more attention be devoted to proactively designing products and environments that are inclusive of everyone.

UD is defined as "the design of products and environments to be usable by all people, to the greatest extent possible, without the need for adaptation or specialized design" (The Center for Universal Design, n.d.). Universally designed courses benefit a broad audience that includes students who are blind and using screen reader technology, who are deaf, whose first language is not English, who have varying levels of technology expertise, who come from different cultural backgrounds, and who have other diverse characteristics. Universally designed courses are accessible, usable, and inclusive. Although these three characteristics are related, they have distinct meanings (Burgstahler, 2020). In the case of online learning, when a student who is blind 
is not able to read the syllabus with a screen reader, the document is inaccessible; a course is not very usable when learning modules are inconsistent in their organization; group assignments are not inclusive when students with disabilities must complete an alternative assignment because the technology or materials required to work in small groups is not accessible to them.

Originally applied to architecture and commercial products, UD was later used for designing websites and other technologies. Three sets of principles underpin a UD framework for the design of any course (Burgstahler, 2020). Principles for the UD of any product or environment relate to equitable use, flexibility in use, simple and intuitive use, perceptible information, tolerance for error, low physical effort, and size and space for approach and use. UD has specifically informed teaching and learning activities. For example, Universal Design for Learning (UDL) principles were developed by the Center for Applied Special Technology (CAST) to apply the UD paradigm to the design of curricula and learning environments, ensuring multiple means for representation, action, expression, and engagement (Rose, Meyer, \& Hitchcock, 2005). UD also underpins the Web Content Accessibility Guidelines (WCAG) whose principles ensure that universally designed IT is perceivable, operable, understandable, and robust (Web Accessibility Initiative, n.d.). All three sets of principles apply to online learning; UD principles provide overall guidance in the development of online learning and physical spaces that support it (e.g., design of workspaces to support computer access); UDL principles are particularly useful when designing curriculum and pedagogy; WCAG principles guide the design of technology and digital materials used to deliver online learning that is accessible, usable, and inclusive. Each of the three sets of principles that underpin UD, UDL, and WCAG have a long history, well developed guidelines, and tested practices (Center for Universal Design in Education, n.d.). 


\section{UD Practices for Online Learning}

Many actions have been recommended to improve the accessibility, usability, and inclusiveness of online learning. Even the popular Quality Matters (QM) Rubric of eight benchmarks for high quality online courses, which was developed by an international collaboration, includes “accessibility and usability” as its eighth standard (Quality Matters, n.d.). UD steps that instructors can take as they develop online courses are shared in the next section of this article.

When applying the UD paradigm, instructors consider each potential student to have a wide range of characteristics as they plan courses. They strive to ensure access to and inclusion of students who live in different time zones, have a variety of busy schedules, and have a wide range of interests and abilities to see, hear, speak, attend to tasks, organize diverse concepts, use technology, read/speak English, etc.

\section{Recommendations from Students}

A few publications report recommendations of students with disabilities who have taken online courses (e.g., Durre, Richardson, Smith, Shulman, \& Steele, 2015; Schelly, Davies, \& Spooner, 2011; Soria, Horgos, Chirikov, \& Jones-White, 2020; University of Washington, 2019). For example, in an accessible online learning conference, students with disabilities made the following recommendations to online learning developers and educators for making online courses more accessible, usable, and inclusive.

- Offer multiple ways to gain knowledge, such as through a video paired with printed materials.

- Provide all materials that are accessible to students with disabilities at the same time they are provided to other students. 
- Caption videos to benefit a wide variety of students, including English language learners, those in noisy (e.g., airports) or noiseless (e.g., libraries, buses) environments, individuals who want to search content, and people with hearing and learning disabilities.

- Design videos to include audio content for visual elements of a video whenever possible (e.g., have the credits and other information at the end of a video spoken by the narrator) to maximize access for individuals who are blind or otherwise cannot see the screen. Consider adding audio description to describe other key elements of the content presented visually.

- Provide text descriptions for all visuals.

- Use accessibly designed documents.

- Engage with students in multiple ways.

- In online discussions, to help students, especially those with learning and communication challenges, provide a specific focus to each discussion question, provide guidance in how to answer the question, engage in and guide the discussion, and summarize the group of responses. (University of Washington, 2019)

\section{Recommendations from Practitioners and Researchers}

Many UD tips have been presented in the literature (e.g., Baucham, 2020; Burgstahler, 2021; Case \& Davidson, 2011; Chambers, Varoglu, \& Kasinskaite-Buddeberg, 2016; Dell, Dell, \& Blackwell, 2015; Fichten, et al., 2009; Hollingshead, 2018; Houston, 2018; Keeler \& Horney, 2007; Raes, Schellens, DeWever, \& Vanderhover, 2012; Seale \& Cooper, 2009; Smith, 2020; Thomson, Fichten, Havel, Budd, \& Asuncion, 2015; Tsuei, 2012; University of Washington, 2019; Vasquez, Forbush, Mason, Lockwood, \& Gleed, 2011). Listed below are tips drawn from 
this literature; some validate those recommended by students in the list above; many are relatively easy for instructors to build into work flows as they design or improve courses.

- Caption videos.

- Present content using a consistent layout.

- Use sans serif fonts on uncluttered pages with plain backgrounds of high contrast and use color combinations that can be seen by those who are colorblind or ensure that it is not necessary for a person to perceive color to understand content or make choices for entering content.

- Design content to be accessible to individuals using screen readers, for example, by putting text within the content pages of a learning management system (LMS), avoiding the creation of PDFs unless they are designed using accessibility standards, and structuring headings and lists using style features built into an LMS, word processors, and presentation software.

- Use descriptive wording for hyperlinked text that makes sense out of context. For example, it is better to use "UDL guidelines" for link text rather than "click here" because screen readers can skip from link text to link text to read aloud this useful information to a user without reading the surrounding text.

- Provide concise alternative text descriptions of content presented within images. For example, if you present a table, use the alternative text feature of the LMS or other software to insert a description relevant to the content presented in the image for a screen reader to vocalize.

Apply UD to teaching practices by following these recommendations:

- Assume students have a wide range of technology skills and tell them how they can 
gain the technology skills needed for course participation.

- Offer multiple ways to learn (e.g., in a combination of text, video, audio, and/or image format), demonstrate knowledge, (e.g., different types of test items, portfolios, presentations, discussions), and engage with fellow students and the instructor.

- Make instructions and expectations clear for activities, projects, and assigned reading.

- Use plain language, spell acronyms, define terms, and avoid or define jargon.

- Avoid including extraneous facts along with critical content.

- Use examples and assignments relevant to learners with a wide variety of interests and backgrounds.

- Offer outlines and other scaffolding tools to help students learn.

- Provide adequate opportunities for practice and feedback on project parts with corrective opportunities.

- Allow adequate time for activities, projects, and tests (e.g., give details of project assignments in the syllabus so that students can start working on them early).

Instructors should also be prepared to make accommodations if some aspects of a course are not accessible. Information that further justifies these practices and tells how they can be implemented are readily available on the Internet (e.g., Burgstahler, 2021; CAST, n.d.; The Center for Universal Design in Education, n.d.)

\section{Conclusion}

Increasing numbers of courses offered online as a result of the COVID19 pandemic have shed light on current online opportunities that are not accessible to, usable by, and inclusive of all potential students, including those with disabilities. Application of a UD framework has the 
potential to benefit multiple marginalized groups and build upon the abilities, strengths, and interests of all learners.

\section{References}

Anderson, A. (2020). Universal design online and students on the Autism Spectrum: Is it a match?. In D. Schmidt-Crawford (Ed.), Proceedings of Society for Information Technology \& Teacher Education International Conference (pp. 1968-1974).

Baucham, M. S. (2020). A transcendental phenomenological study of faculty use of Universal Design For Learning that includes multiple means of expression while teaching online general education courses at a technical college. Liberty University, Lynchburg, VA.

Burgstahler, S. (2020). Creating inclusive learning opportunities in higher education: A universal design toolkit. Harvard Education Press.

Burgstahler, S. (2021). 20 tips for teaching an accessible online course. DO-IT, University of Washington. Retrieved from http://www.washington.edu/doit/20-tips-teachingaccessible-online-course

CAST (n.d.). UDL on Campus. Author. Retrieved from http://udloncampus.cast.org/home The Center for Universal Design. (n.d.). About UD. North Carolina State University. Retrieved from http://www.ncsu.edu/ncsu/design/cud/about_ud/about_ud.htm

The Center for Universal Design in Education (n.d.). Universal design of online learning. University of Washington. Retrieved from https://www.washington.edu/doit/programs/center-universal-designeducation/resources/published-books-and-articles-about-universal\#block-viewsviewblock5b-block-9 
Case, E. C., \& Davidson, R. C. (2011). Accessible online learning. New Directions for Student Services, 2011(134), 47-58.

Chambers, D., Varoglu, Z., \& Kasinskaite-Buddeberg, I. (2016). Learning for all: Guidelines on the inclusion of learners with disabilities in open and distance learning. Paris, France: United National Educational, Scientific, and Cultural Organization.

Dell, C. A., Dell, T. F., \& Blackwell, T. L. (2015). Applying universal design for learning in online courses: Pedagogical and practical considerations. Journal of Educators Online, $13(2), 166-192$.

DePoy, E., \& Gibson, S. (2008). Disability studies: Origins, current conflict, and resolution. Review of Disability Studies, 4(4), 33-40.

Durre, I, Richardson, M., Smith, C., Shulman, J., \& Steele, S. (2015). Universal design of instruction: Reflections of students. In S. Burgstahler (Ed.), Universal design in higher education: From principles to practice, Second edition (pp. 117-130). Harvard Education Press.

Fichten, C. S., Ferraro, V., Asuncion, J. V., Chwojka, C., Barile, M., Nguyen, M. N., Wolforth, J. (2009). Disabilities and e-learning problems and solutions: An exploratory study. Educational Technology and Society, 12(4), 241-256.

Gabel, S., \& Peters, S. (2010). Presage of a paradigm shift: Beyond the social model of disability toward resistance theories of disability. Disability \& Society, 19(6), 585-600.

Hollingshead, A. (2018). Designing engaging online environments: Universal design for Learning principles. In Cultivating diverse online classrooms through effective instructional design (pp. 280-298). IGI Global. 
Houston, L. (2018) Efficient strategies for integrating universal design for learning in the online classroom. Journal of Educations Online, 15(3).

Keeler, C. G., \& Horney, M. (2007). Online course designs: Are special needs being met? The American Journal of Distance Education, 21(2), 61-75.

Kinash, S., Crichton, S., \& Kim-Rupnow, W. S. (2004). A review of 2000-2003 literature at the intersection of online learning and disability. The American Journal of Distance Education, 18(1), 5-19.

Quality Matters. (n.d.). Rubric. Retrieved from https://www.qualitymatters.org/rubric

Raes, A., Schellens, T., De Wever, B., \& Vanderhover, E. (2012). Scaffolding information problem solving in web-based collaborative inquiry learning. Computers \& Education, $59,82-94$.

Roberts, K. D., Satkyjgykyjova, M., \& Park, H-J. (2015). Universal design for instruction in postsecondary education: A literature review of empirically based articles. In Universal design in higher education: From principles to practice (pp. 65-80). Harvard Education Press.

Rose, D. H., Meyer, A., \& Hitchcock, C. (Eds.). (2005). The universally designed classroom: Accessible curriculum and digital technologies. Harvard Education Press.

Schelly, C. L., Davies, P. L., \& Spooner, C. L. (2011). Students perceptions of faculty implementation of universal design for learning. Journal of Postsecondary Education and Disability, 24(1), 17-30.

Seale, J., \& Cooper, M. (2009). E-learning and accessibility: An exploration of the potential role of generic pedagogical tools. Computers and Education, 54(4), 1107-1116. 
Smith, C. (2020). Challenges and opportunities for teaching students with disabilities during the Covid-19 pandemic. International Journal of Multidisciplinary Perspectives in Higher Education, 5(1), 167-173.

Soria, K. M., Horgos, B., Chirikov, I., \& Jones-White, D. (2020). The experiences of undergraduate students with physical, learning, neurodevelopmental, and cognitive disabilities during the COVID-19 pandemic. SERU Consortium, University of California - Berkeley and University of Minnesota.

Thomson, R., Fichten, C. S., Havel, A., Budd, J., \& Asuncion, J. (2015). Blending universal design, e-learning, and information and communication technologies. In S. Burgstahler (Ed.), Universal design in higher education: From principles to practice, Second edition (pp. 275-284). Harvard Education Press.

University of Washington. (2019). AccessCyberlearning 2.0 capacity building institute proceedings. Retrieved from https://www.washington.edu/doit/accesscyberlearning-20capacity-building-institute-2019

Vasquez, E., Forbush, D. E., Mason, L. L., Lockwood, A. R., \& Gleed, L. (2011). Delivery and evaluation of synchronous online reading tutoring to students at-risk of reading failure. Rural Special Education Quarterly, 30(3), 16-26.

Web Accessibility Initiative. (2018). Web Content Accessibility Guidelines 2.1. Retrieved from https://www.w3.org/TR/WCAG21/

Xu, D., \& Jaggars, S. S. (2014). Performance gaps between online and face-to-face courses: Differences across types of students and academic subject areas. Journal of Higher Education, 85(5), 633-659. 


\section{Acknowledgments}

This article is based on work supported by the National Science Foundation (grant numbers CNS-1539179 DRL-182540, and HRD-1834924). Any opinions, findings, and conclusions or recommendations are those of the author and do not necessarily reflect the policy or views of the U.S. government, and you should not assume its endorsement. 